\title{
Effects of nanosilica to improve the mechanical, electrical and durability properties of fiber- reinforced high-volume processed sugarcane bagasse ash cement mortar
}

Ramasamy Gopalakrishnan ( $\square$ gopalsrmphysics@gmail.com )

SRM University https://orcid.org/0000-0002-3244-1375

RAVI KAVERI

SRMIST: SRM Institute of Science and Technology

A JohnKirubahar

SRM Institute of Science and Technology

\section{Research Article}

Keywords: Nanosilica, pozzolanic activity, electrical resistivity, durability, sugarcane bagasse ash

Posted Date: February 12th, 2021

DOl: https://doi.org/10.21203/rs.3.rs-216484/v1

License: (c) (1) This work is licensed under a Creative Commons Attribution 4.0 International License.

Read Full License 


\section{Abstract}

Nanosilica (NS) has attracted wide variety of usage as cement ingredients. While many other studies have focused on early cement hydration and hardening properties, there is less data available on the impact of NS on the behavior of fiber-reinforced high-volume sugarcane bagasse cement mortar (HVSCBAM). The effects of NS on the fiber-reinforced durability of HVSCBAM, having the properties of sugarcane bagasse ash/binder in an average of $50 \%$ by weight, have been presented in detail in this study. Four NS/binder weight ratio dosages of $0 \%, 0.5 \%, 1.0 \%$ and $1.5 \%$ of and another four total PVA fiber/volume ratio dosages of $0 \%, 0.2 \%, 0.5 \%$ and $1.0 \%$ were used. Compared to $0.2-1$ vol.\% of PVA fiberreinforced HVSCBAM, the $1.5 \mathrm{wt} . \%$ of NS would enhance the compressive strength further. Various reports on mineralogy and microstructure have demonstrated that NS facilitates fiber/matrix bonding. These conclusions provide an insight into the pozzolanic materials of cement that are used in a large volume in the designs and applications of nanoparticles.

\section{Full Text}

Due to technical limitations, full-text HTML conversion of this manuscript could not be completed. However, the manuscript can be downloaded and accessed as a PDF.

\section{Figures}

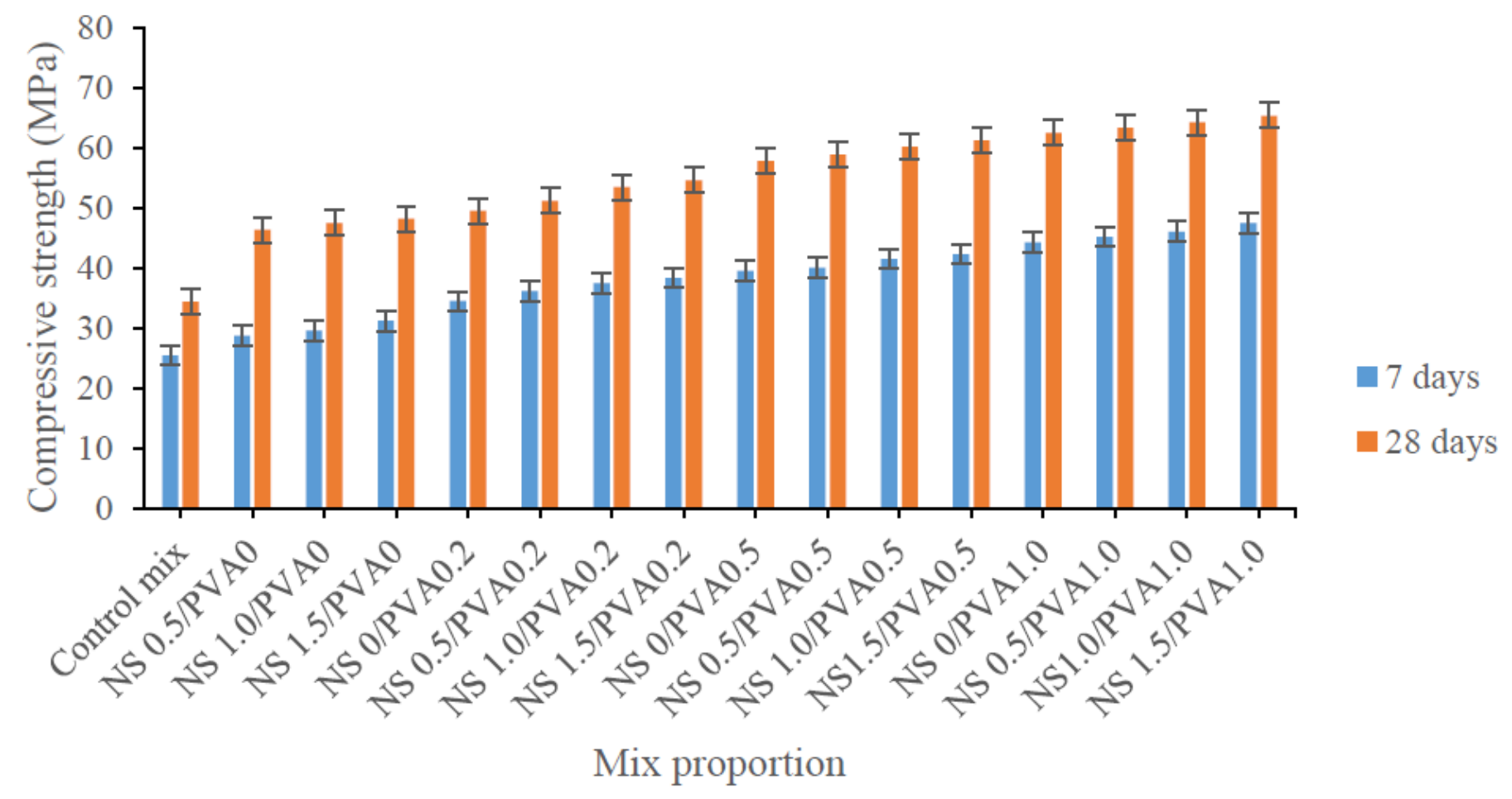

Figure 1 
Compressive strength of mortars with varied NS/PVA hybrid at the age of 7,28 days.

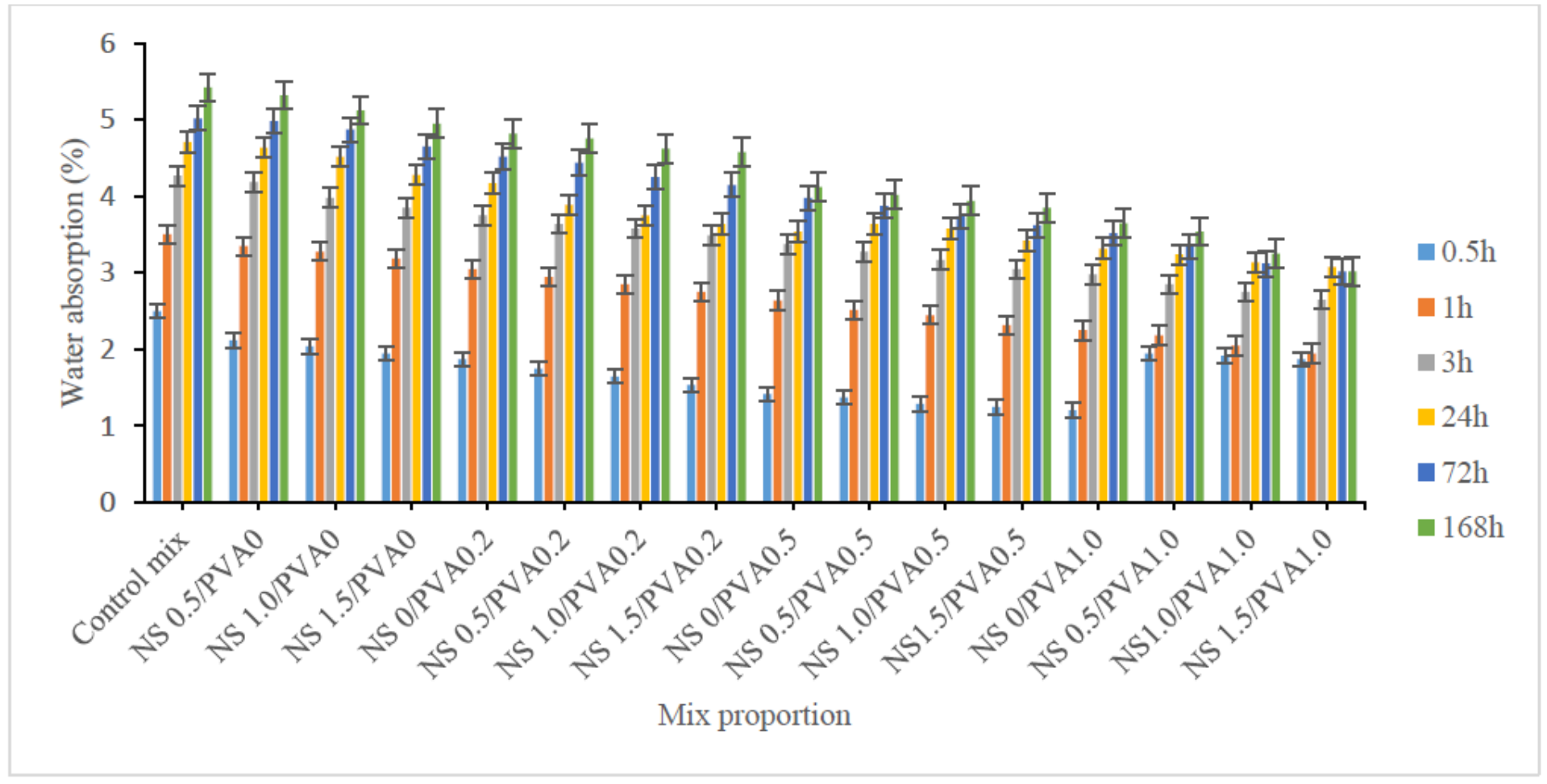

Figure 2

Water absorption of mortars with varied NS/PVA hybrid at the age of 28 days.

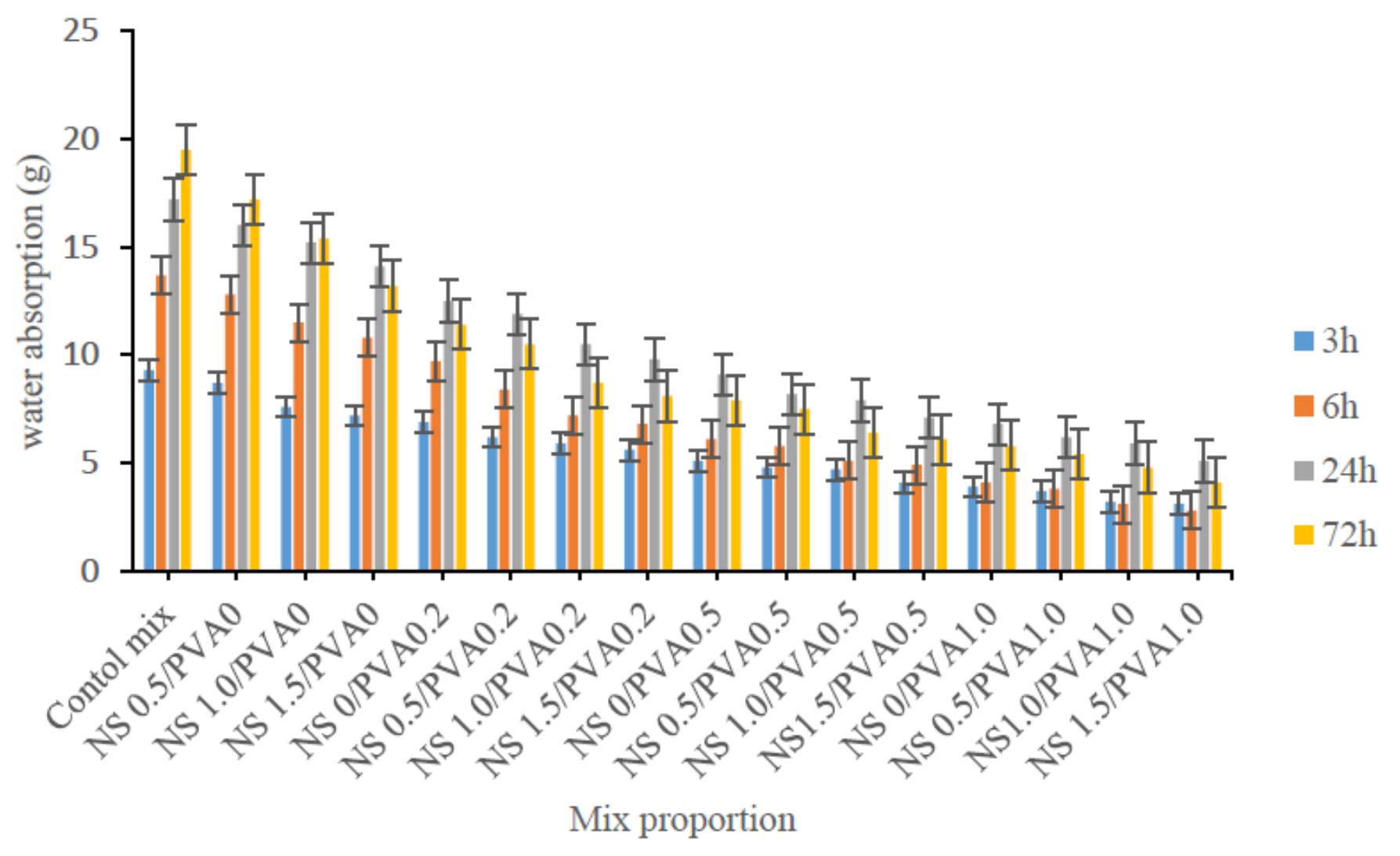


Figure 3

Capillary absorption of mortars with varied NS/PVA hybrid at the age of 28 days.

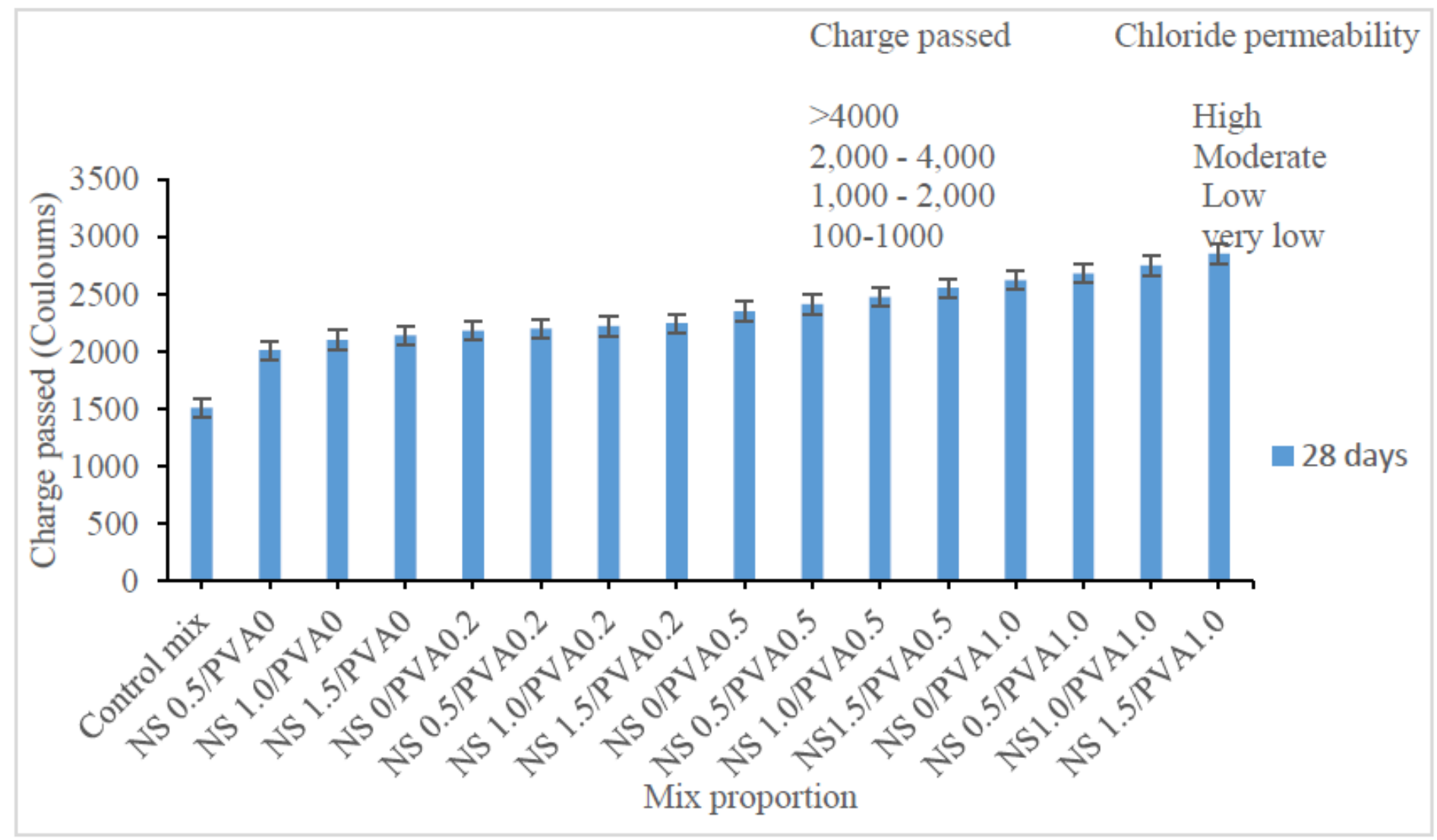

Figure 4

Rapid chloride permeability of mortars with varied NS/PVA hybrid at the age of 28 days. 


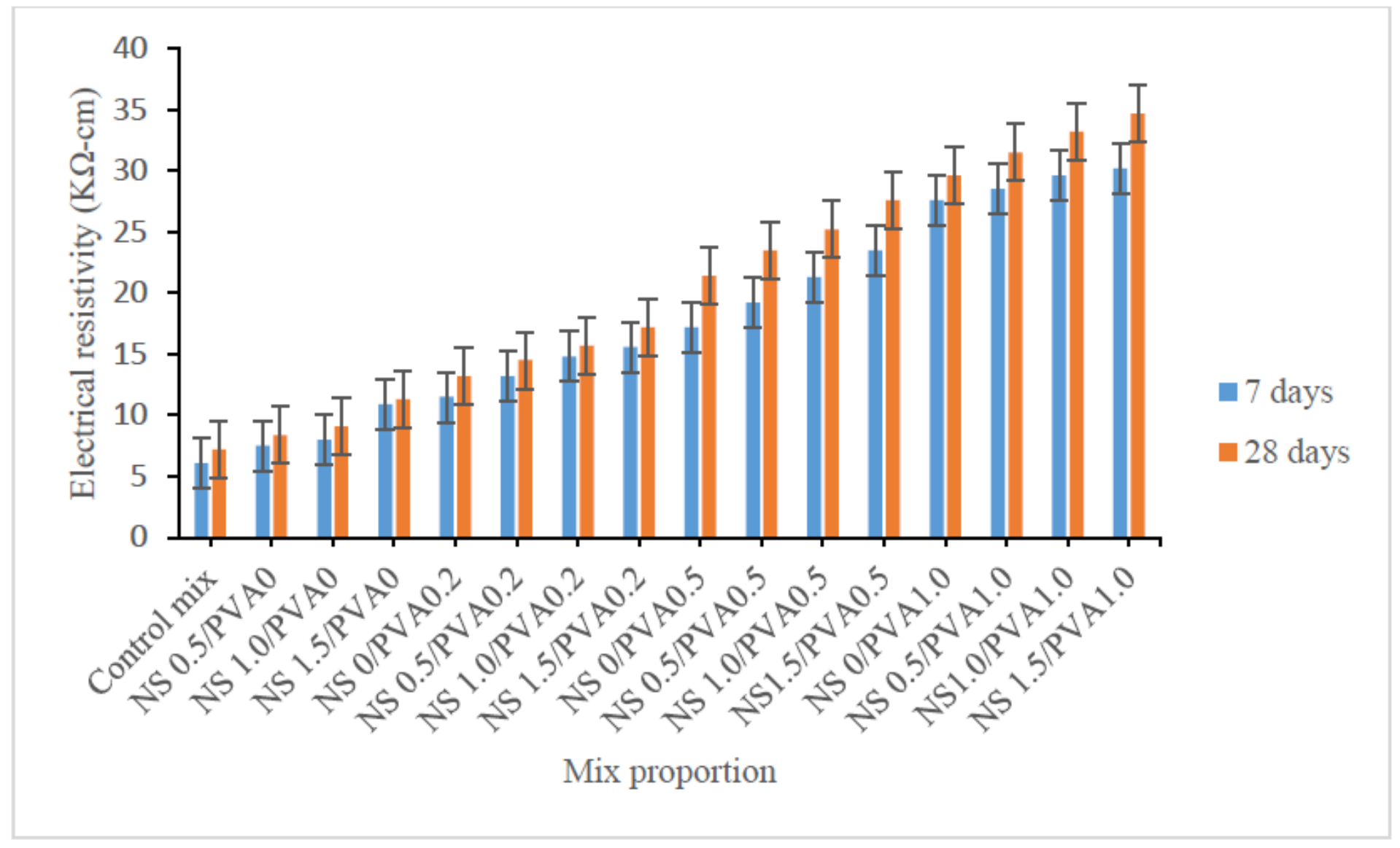

Figure 5

Electrical resistivity of mortars with varied NS/PVA hybrid at the age of 7, 28 days. 


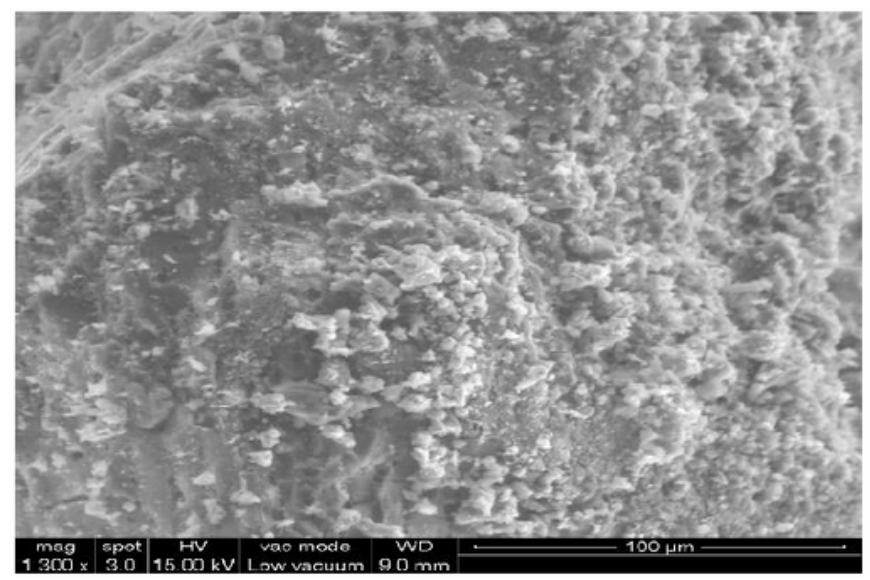

Fig.6a

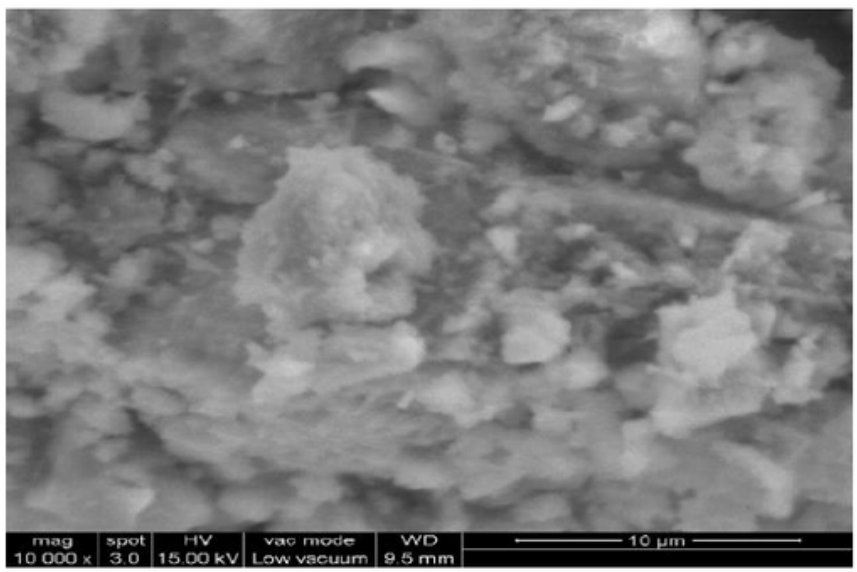

Fig.6c

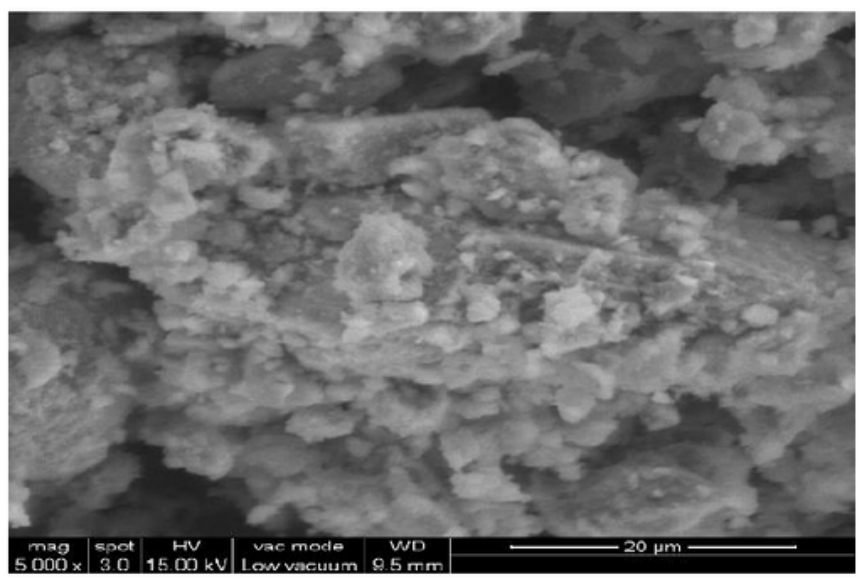

Fig.6b

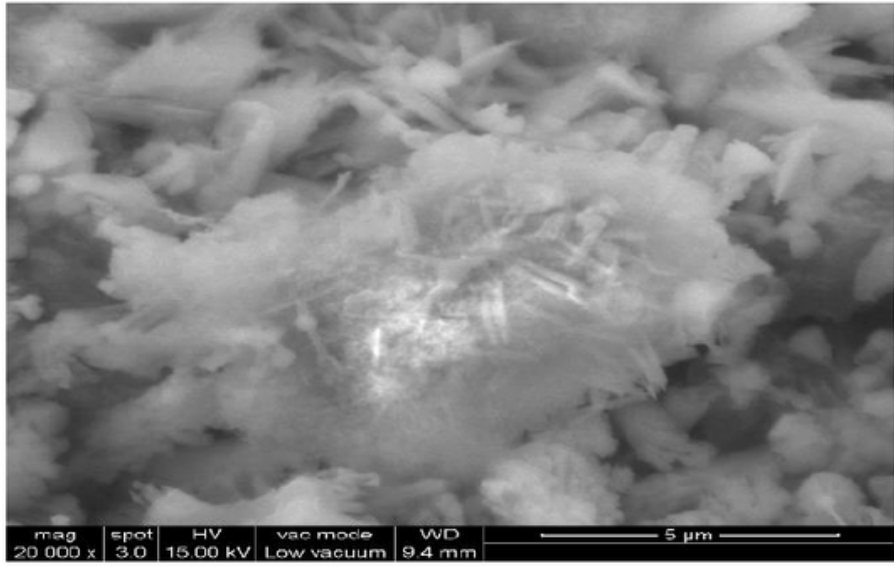

Fig.6d

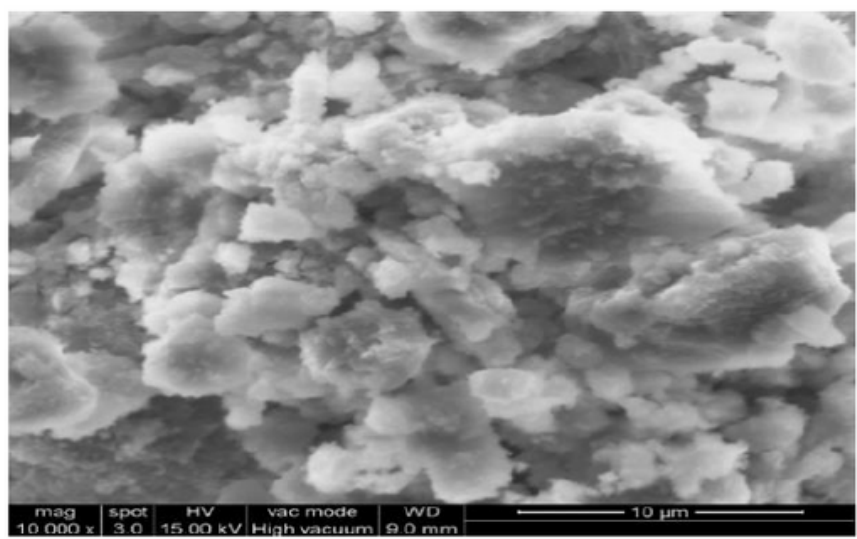

Fig.6e

Figure 6

SEM photograph of (a) control mixture (b) Mixture (NS1.0/PVA0) (c) Mixture (PVA0.5/NS1.0) (d) Mixture (NS 1.5/PVA0.5) (e) Mixture (NS 1.5/PVA1.0) 

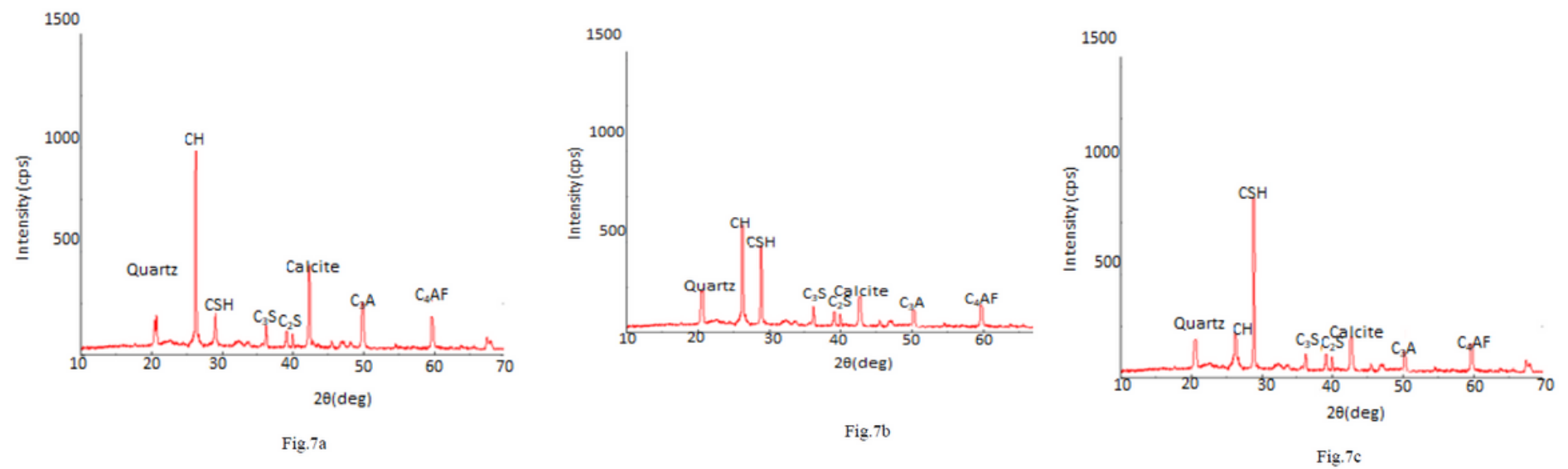

Figure 7

XRD Pattern of (a) control mixture (b) Mixture (NS1.0/PVA0) (c) Mixture (NS 1.5/PVA1.0) 